

\section{Cursos Pré-Vestibulares Populares em Salvador: Experiências Educativas em Movimentos Sociais}

\begin{abstract}
RESUMO: O presente artigo relata o resultado da pesquisa sobre as experiências educativas dos cursos pré-vestibulares populares em Salvador, sua origem e características de cultura organizacional, enquanto espaços de educação não-formal ligados a movimentos sociais na busca da construção de valores de cidadania ativa, etnicidade e solidariedade com os seus alunos.
\end{abstract}

PALAVRAS-CHAVE: movimentos sociais, universidade, interculturalismo

\section{Introdução}

Os cursos preparatórios pré-vestibulares organizados por diversas entidades e movimentos sociais, especialmente a partir da década de 1990, se multiplicaram como iniciativas de educação não-formal e popular. Compreendemos, neste trabalho, educação não-formal como "toda atividade educacional organizada, sistemática, executada fora do quadro do sistema formal para oferecer tipos selecionados de ensino a determinados subgrupos da população"(LA BELE, 1986).

A educação pode se configurar como aquela formal, sistemática, com o objetivo de inculcar sobre as novas gerações os valores hegemônicos na sociedade, e com sistemas reconhecidos, organizados ou normatizados pelo Estado. A educação também se dá nas famílias, nos grupos sociais, no grupo de amigos, nas igrejas, de maneira informal, inculcando o arbitrário cultural da classe ou grupo social ao qual o indivíduo pertence ou o arbitrário cultural dominante (BOURDIEU; PASSERON, 1982). Mas a educação não-formal também é expressiva na sociedade, especialmente em movimentos e organizações da sociedade civil.

Consideramos os cursos pré-vestibulares analisados como uma modalidade de educação popular, pois é voltada especificamente para os setores "subalternos" da sociedade, ou organizada por esses setores. Esses setores acima referidos são aqueles que pelos dados oficiais estão excluídos ou mais excluídos dos serviços de educação como um todo e da Educação Superior em especial.

Na sociedade brasileira, fica clara a reprodução das desigualdades sociais pelo acesso diferenciado à educação, de acordo com
Penildon Silva Filho

Doutorando em Educação Professor da Faculdade Baiana de Ciências, Faculdade Hélio Rocha penildonsilvafilho@yahoo.com.br 
o Censo Escolar organizado pelo Instituto Nacional de Pesquisas Educacionais (INEP), ligado ao Ministério da Educação (MEC). Essa diferenciação ocorre pela qualidade das escolas, que varia de região para região, e pelo fato de que uma parcela minoritária da população, com rendimentos superiores, está em escolas particulares de qualidade superior às escolas públicas e outras escolas particulares voltadas à classe média baixa. Essas pesquisas também indicam uma desvantagem dos negros no acesso à educação de forma geral, especialmente no acesso à Educação Superior, em todos os estratos sociais. Esse foi um dos motivos da organização dos cursos pré-vestibulares populares, viabilizar o acesso de setores sub-representados na Educação Superior a esse nível de ensino, ao lado de outros, como trabalhar o engajamento social, a cidadania e o reconhecimento social desses setores excluídos.

Devido à massificação do acesso à Educação Básica, como ficou atestado no último Censo Escolar do MEC, o contingente do alunado que termina o ensino médio cresceu e ainda continua a crescer, aumentando a demanda pela Educação Superior, justamente nos setores mais pobres da sociedade, pois é justamente esse segmento que está tendo uma ampliação de seu acesso à educação básica no momento atual. Entretanto, não há uma criação de vagas na Educação Superior na mesma proporção que o acesso e a progressão desses segmentos acima citados.

Os processos de avaliação do próprio MEC, através do Sistema de Avaliação da Educação Básica, demonstram uma baixa qualidade da educação pública oferecida a esses mesmos segmentos, que estão freqüentando a escola pública e que cada vez mais procuram ser admitidos na Educação Superior. O setor público da Educação Superior tem um aumento de vagas inferior ao ritmo de crescimento de egressos do ensino médio. O aumento de vagas das faculdades e universidades privadas é bem mais significativo, mas as condições socioeconômicas do público egresso de escola pública são um obstáculo à sua entrada nos estabelecimentos particulares.

As dificuldades de acesso à universidade desse segmento egresso de escolas públicas, especialmente de negros e pobres, ao lado do fortalecimento de iniciativas populares de organização social que lutam por direitos da cidadania, geraram uma gama significativa de experiências educativas de cursos preparatórios ao vestibular, os pré-vestibulares populares. São cursos organiza- 
dos por movimentos e entidades de caráter não oficial e que não se concentram apenas na preparação técnica para enfrentar as provas dos vestibulares, mas têm apresentado um discurso de engajamento na construção da cidadania dos seus alunos, da valorização da identidade social, racial e étnica deles, do fortalecimento do sentimento de solidariedade dos grupos socialmente excluídos. Esses cursos também afirmam ter uma gestão diferente das escolas oficias e tradicionais, com um funcionamento e uma cultura organizacional distinta.

Os cursos seriam espaços de socialização política dos alunos, de educação "de novos valores" efetivamente. Ao mesmo tempo, os cursos vêm empreendendo, em muitos lugares, uma luta pela ampliação das oportunidades para os segmentos socialmente e historicamente excluídos entrarem na universidade.

As iniciativas dos cursos populares, em sua maioria ligados às organizações negras, tornaram-se um movimento forte, com vários cursos, ações políticas e debates na sociedade civil e na mídia sobre iniqüidade social e oportunidades educacionais. Essas movimentações tiveram como resposta do MEC um programa institucional, o Diversidade na Universidade, voltado à inclusão de afrodescendentes, indígenas e outros grupos socialmente excluídos das universidades. Esse Programa tem como principal foco de investimentos, conseguidos através de um convênio entre o governo federal e o Banco Mundial, o financiamento dessas iniciativas, o que demonstra a força alcançada e o reconhecimento já manifesto por parte do Estado brasileiro.

Os cursos pré-vestibulares populares fazem críticas aos cursos pré-vestibulares comerciais, e criam sua identidade principalmente a partir da negação do padrão comercial dos cursos no mercado. Teriam então caráter não comercial. Eles partem do pressuposto de serem um movimento social sem o objetivo principal de remuneração, então se aproximam do tipo de trabalho das ONGs no terceiro setor, de trabalho voluntário e do princípio da fraternidade e da doação; tentam ganhar a simpatia ou adesão dos alunos para sua causa, muitas vezes convidando-os a participar do movimento negro, de bairro, da ONG, da igreja, e outros promotores dessas iniciativas.

Grande parte dos cursos alternativos defende que sua estrutura de funcionamento é similar ao do movimento, com assembléias, debates e participação democrática de alunos e professo- 
res. Afirmam que trabalham com conteúdos de "cidadania", valorização da identidade étnica, racial, social nas salas de aula. A1guns ainda elaboram uma formulação de que o principal não é a aprovação no vestibular; mas a "tomada de consciência" das pessoas, o seu engajamento nas lutas da entidade que organizou o curso, tentando criar um espaço de convivência entre alunos, professores e coordenação visando a formação de grupos, com uma mística, uma identidade e uma dinâmica interna.

Recentemente, esses cursos começaram um processo de mobilização social com várias reivindicações, caracterizando um movimento social. Esse processo ganhou maior visibilidade especialmente a partir da Conferência Anti-Racismo em Durbam, na África do Sul, em 2001. A delegação brasileira levou uma proposta de estabelecer cotas para negros nas universidades públicas, a exemplo do que ocorre nos Estados Unidos, e os cursos populares ligados ao movimento negro participaram ativamente da mobilização pré-conferência de Durbam e das mobilizações posteriores. Devido à dinâmica do encontro, que estabelecia um peso maior às organizações da sociedade nas delegações nacionais, a delegação brasileira defendeu essa proposta de cotas para negros no ingresso nas universidades, no encontro internacional, apesar da posição contrária do governo brasileiro.

Mas os cursos pré-vestibulares populares conseguem interferir realmente sobre a visão de mundo, a identidade e a participação cidadã de seus alunos? Eles se constituem com uma cultura organizacional voltada para o desenvolvimento da democracia, da cidadania e da participação dos alunos? Esses cursos seriam realmente um novo movimento social de reivindicação pela educação? Foi necessário averiguar a práxis pedagógica dos cursos, seu funcionamento, e comparar com o anunciado ou o antevisto nas suas mobilizações sociais.

Uma hipótese de nossa pesquisa foi que os cursos pré-vestibulares populares são experiências de movimentos sociais, com funcionamento em rede, que tentam democratizar o acesso à universidade. Entretanto, cursos pré-vestibulares influenciam pouco na aprovação dos alunos, pois essa aprovação é resultante de um longo período de estudos em escolas que adestrem os alunos para responder às questões de testes que aferem o volume de informações do aluno ou, caso os exames vestibulares procurem aferir competências, também não será em um ano que essas se- 
rão desenvolvidas significativamente. Essa tentativa de democratizar o acesso à universidade e ampliar o acesso de setores excluídos se dá pela organização de movimento social reivindicativo.

A segunda hipótese foi que esses movimentos também se constituíram em espaços de socialização e aprendizado político para os alunos e tentam contribuir para a formação de identidade e da cidadania ativa. Mas o sucesso desses objetivos está condicionado a uma experiência anterior dos próprios alunos, um habitus, pois o tempo do curso e as características do pré-vestibular impedem que um trabalho pedagógico isolado tenha sucesso nesse objetivo anunciado pelos cursos. Essa terceira hipótese caso fosse refutada, não invalidaria as duas primeiras.

\section{A cidadania dos movimentos sociais dos cursos pré-vestibulares populares}

O conceito de cidadania aparece muito nos discursos dessa modalidade de educação não-formal dos cursos pré-vestibulares populares e podemos defini-lo como de cidadania ativa, que tem uma dupla face: a participação social, mais próxima do que Touraine (1994) identifica como representação de interesses, e o sentido e sentimento de pertença à sociedade para interagir e respeitar as regras sociais e defender seus direitos também. Esse conceito de cidadania ativa foi usado para identificar o processo de superação da situação de não participação política, subserviência política e de tutela, desconhecimento dos direitos e falta do sentido de pertença. (DALLARI, 1998:8; FGV, 1986; FERREIRA, 1993; GOHN, 1995; 1999:112; TOURAINE, 1994).

Podemos definir o conceito de cultura organizacional, que foi usado na análise do cotidiano dos cursos pré-vestibulares populares, mas antes é importante definir o próprio conceito de cultura, pois ele é importante para a compreensão de cultura escolar e do debate estabelecido nos cursos populares sobre a valorização da cultura e da etnicidade negras ou da cultura popular.

O conceito de cultura não é um consenso no momento atual e sofreu mudanças ao longo da história, inclusive refletindo o processo de disputas internas numa sociedade e as disputas de poder entre sociedades diferentes. A definição de "cultura" de forma específica tinha implicações sobre as relações de poder e sua justificação e por isso não é possível entendê-lo sem fazer essa genealogia. 
Podemos identificar um conceito de cultura mais apropriada à nossa pesquisa como "um discurso simbólico coletivo sobre conhecimentos, crenças e valores" (KUPER, 2002).

O conceito de Cultura Organizacional usado é o formulado por Schein, citado por Teixeira(2000):

(...) um modelo de concepções básicas-inventadas, descobertas ou desenvolvidas por um dado grupo ao aprender a lidar com seus problemas de relação externa e integração interna - que funcionaram bem o suficiente para serem consideradas válidas e por isso ensinadas aos novos membros como a maneira correta de perceber e sentir em relação a esses problemas (SCHEIN,1991: p. 9 apud TEIXEIRA, 2000)

Com relação ao conceito de habitus, Bourdieu(1982)o definiu como "aquilo que se adquiriu, mas que se encarnou no corpo de forma durável sob a forma de disposições duráveis", ou então "um sistema de esquemas de geradores de práticas e de esquemas de percepção de práticas". O habitus dos alunos foi importante para compreender o trabalho dos cursos pré-vestibulares populares.

Um objetivo sempre presente nos discursos dos cursos prévestibulares populares, aqueles dirigidos pelas organizações do movimento negro e outras iniciativas, é estimular e valorizar a identidade e a solidariedade do grupo, como elemento fundamental não somente para conseguir segurança para as provas de vestibular, mas muito mais para uma mudança de postura frente à vida social dos indivíduos e dos grupos constituídos por eles. As identidades sociais, étnicas e raciais são as mais usadas nesses discursos, especialmente as duas últimas.

O conceito de etnia é definido por Barth (OLIVEIRA, 1976). Segundo ele, um grupo étnico designa uma população que se perpetua principalmente por meios biológicos; compartilha de valores culturais fundamentais, postos em prática em formas culturais num todo explícito; compõem um campo de comunicação e interação; e tem um grupo de membros que se identifica e é identificado por outros como constituinte de uma categoria distinguível de outras categorias da mesma ordem.

Assim, o movimento negro atual trabalha mais com a etnicidade, ou seja, a valorização dos aspectos estéticos do grupo, da ancestralidade, do resgate da história dos negros, da reconstituição e valorização de sua cultura, o resgate e divulgação de seus heróis, de 
suas lutas, ou seja, a sua auto-afirmação. O conceito de raça é mais polêmico de se definir, uma vez que há autores que sustentam que não é correto afirmar existirem raças, pois só existe a raça humana, e o que teríamos no planeta são etnias diferentes. É o que explica Rex (1983, p. 3-4), citado por Guimarães (1995):

1) Raça é um conceito taxonômico de limitado alcance para classificar os seres humanos, podendo ser substituído com vantagens pela noção de população. Enquanto o primeiro termo se refere a "grupos humanos que apresentam diferenças físicas bem marcadas e primordialmente hereditárias", o segundo se refere a "grupos cujos membros se casam com outros membros do grupo mais freqüentemente que com pessoas de fora do grupo e, desse modo, apresentam um leque de características genéticas relativamente limitado".

2) De qualquer modo, chamem-se esses grupos de raças ou populações, a diversidade genética no interior deles não difere significativamente, em termos estatísticos, da diversidade encontrada entre grupos distintos. Desse modo, nenhum padrão sistemático de traços humanos - com exceção do grupo sanguíneo - pode ser atribuído a diferenças biológicas. E esse último traço, por seu turno, não coincide com os grupos usualmente chamados de raças. (GUIMARÃES, 1995)

A discriminação contra os negros, contra os pobres, os excluídos faz parte dessa situação de desigualdade. Na contemporaneidade, o processo de discriminação não é percebido apenas pelos aspectos econômicos, mas pelos socioculturais, e a busca do reconhecimento e pela produção e circulação de bens simbólicos passa a ser uma demanda tão importante quanto a disputa pelos recursos materiais e pelo poder político e de Estado no âmbito de uma sociedade. O assim chamado interculturalismo traz para a arena política outras temáticas, que não são excludentes de demandas anteriores, mas que ganham muito relevo. As questões étnicas, de liberdade de opção sexual, de satisfação pessoal, de felicidade individual perpassam agora o espaço público, quando anteriormente o sistema monocultural insistia em conservá-las no âmbito do espaço privado (SEMPRINI, 1999)

É importante ressaltar que Melucci (2001) e Gohn (2000) também salientam a importância dos movimentos sociais terem o aspecto da auto-estima, e de constituir uma cultura interna que permita a construção de relações internas que mantenham o gru- 
po e o fortaleçam para apresentar uma cara própria à sociedade e também influenciar a cultura mais geral da sociedade.

Consideramos esses cursos pré-vestibulares populares como um movimento social, com um espaço de aprendizado político, de estabelecimento de identidades e de construção de solidariedade, visando transformar a sociedade, seja pela ampliação das oportunidades de educação, seja pela mudança de consciências e posturas para uma cidadania ativa. Isso será conseguido através da formação, entre os alunos, de intelectuais orgânicos por esses cursos para fortalecer a disputa contra-hegemônica no seio da sociedade civil. Os cursos têm o interesse do engajamento dos alunos em suas "causas", procuram criar espaços educativos à semelhança de seus ideais e organizações. Por isso, utilizamos os referenciais gramscianos de intelectual orgânico e disputa de hegemonia para nossa análise.

Esses intelectuais orgânicos atuam nos movimentos sociais, que, segundo Maria da Glória Gohn, em seu livro, Teoria dos Movimentos Sociais, os caracteriza como:

(...)ações sociopolíticas construídas por atores sociais coletivos pertencentes a diferentes classes e camadas sociais, articuladas em certos cenários da conjuntura socioeconômica e política de um país, criando um campo político de força social na sociedade civil. A ações se estruturam a partir de repertórios criados sobre temas e problemas em conflitos, litígios e disputas vivenciados pelo grupo na sociedade. As ações desenvolvem um processo social e político-cultural que cria uma identidade coletiva para o movimento, a partir dos interesses em comum. Esta identidade é amalgamada pela força do princípio da solidariedade e construída a partir da base referencial de valores culturais e políticos compartilhados pelo grupo, em espaços coletivos não-institucionalizados. Os movimentos geram uma série de inovações nas esferas pública (estatal e nãoestatal) e privada; participam direta ou indiretamente da luta política de um país, e contribuem para o desenvolvimento e a transformação da sociedade civil e política. (GOHN, 2000).

\section{Os caminhos da pesquisa}

A pesquisa sobre os cursos pré-vestibulares populares foi de caráter qualitativo, analisando e interpretando a cultura organizacional, do material de trabalho em sala de aula, do imagi- 
nário de professores e alunos e de suas inter-relações nos cursos e com o meio, dentre outros. As necessidades do problema e os objetivos da pesquisa apontaram para a pesquisa documental e eletrônica e para a metodologia do Estudo de Caso.

Em primeiro lugar, fizemos uma pesquisa documental e eletrônica em busca de indicações da atuação dos cursos como movimentos sociais e de suas características de funcionamento em rede. A população dos cursos pré-vestibulares populares é numerosa em termos nacionais.

Concomitantemente, utilizamos o estudo de caso. Nosso recorte de pesquisa foi a cidade de Salvador, que hoje tem um contingente de cerca de 14 cursos pré-vestibulares populares. Pudemos identificar e comprovar o funcionamento efetivo dos seguintes cursos em Salvador: Curso Kilombo Asantewaa, Curso Comunitário, Curso Janira Migliac, Curso da Igreja Filadélfia, Curso Estudar e refletir, Curso Conteúdo, Instituto Cultural Steve Biko, Curso Irmã Baquita, Curso do Centro Social D. Lucas, Curso de Santa Teresinha, Koekilombo-Curso de Plataforma, Curso Milton Santos (IAPI), Curso da ONG Oficina de Cidadania, Curso da Pastoral Afro. Fizemos um estudo de caso com três cursos pré-vestibulares populares em Salvador. Escolhemos um curso ligado ao movimento negro, o Asantewaa, um ligado à Igreja Católica, o curso do Centro D. Lucas Moreira Neves, no Alto do Peru, e o curso Oficina de Cidadania, uma organização não-governamental (ONG). Buscamos conhecer o trabalho e entrevistar os membros do fórum de cursos negros que formulam o material didático para cinco cursos em Salvador, através dos coordenadores do Asantewaa, que fazem parte do fórum.

\section{Um novo movimento social pela educação: Os cursos pré-vestibulares populares}

Os cursos pré-vestibulares populares como movimentos sociais e como redes ficaram bastante ilustrados na nossa pesquisa. Há muito material e documentação de mobilizações dos cursos populares. Há o Movimento dos Sem Universidade (MSU) de São Paulo, anteriormente citado, que conquistou, junto com o Fórum dos cursinhos populares de São Paulo, o direito de uma percentagem de alunos com isenção de taxa nos vestibulares das universidades estaduais paulistas, a USP, a UNESP e a UNICAMP. O MSU e 
o Fórum de cursinhos de São Paulo reuniram-se por meses com as reitorias das instituições, com a coordenação da FUVEST e tiveram a mediação da OAB- Seção São Paulo para conseguir um acordo, e inclusive entraram com ação na justiça para garantir um prazo maior de inscrição dos candidatos a essa isenção. O MSU tem uma programação de atividades durante todo o ano, divulgada por página da Internet, faz pressão sobre os poderes constituídos, como na ocasião em que aprovou no orçamento da cidade de São Paulo recursos para a construção de uma "Universidade Popular" no município.

O Núcleo de Consciência Negra da USP, que tem um cursinho e realiza manifestações anti-racistas dentro e fora da universidade, demonstra também esse caráter de movimento. Há ainda a rede de cursinhos da zona Leste de São Paulo, organizada pela Igreja Católica e que já reúne cerca de 1,5 mil alunos.

A Rede de cursinhos da Educafro, no Rio de Janeiro, sob a coordenação do Frei Davi, da Igreja Católica, além de ter 3 mil alunos, trabalha na perspectiva da identidade racial e realizou manifestações em frente à UERJ, reivindicando mais vagas e cotas para alunos negros e de escolas públicas nas universidades. Uma dissidência da Educafro, o Curso Pré-vestibular para Negros e Carentes (PVNC), também trabalha na mesma perspectiva e ajudou a organizar, com recursos do Ministério da Justiça, em 2002, um encontro de cursos populares no Rio de Janeiro com participantes de São Paulo, Mato Grosso do Sul e Rio de Janeiro.

Na Bahia, nos anos de 2001 e 2002, também foram conquistadas cotas de isenção de taxa no vestibular na UFBA e na UNEB, como conseqüência de manifestações no mês de agosto de 2001, iniciadas pelo curso Oficina de Cidadania, e negociações durante o ano de 2002. O Instituto Cultural Steve Biko também acionou o Ministério Público Federal na Bahia, que concedeu liminar, a seu pedido, para isentar todos os alunos que prestariam vestibular em 2002.

Os cursos realizam manifestações e atos e conseguem espaço na imprensa pautando o espaço público da sociedade com suas reivindicações, como é o caso das cotas para estudantes negros, isenção de taxa no vestibular, lutas por mais vagas, abertura de mais universidades e o combate ao racismo e à discriminação. A discussão sobre racismo no Brasil foi intensificada a partir dessas mobilizações, como pode ser visto em várias colunas de jornal, a exemplo do dia 21 de dezembro de 2002, com o debate sobre con- 
ceito de "raça" (FOLHA, 2002). No dia 8 de setembro de 2002, o Ministro da Educação afirmou que as políticas universalistas para a educação foram bem sucedidas (FOLHA, 2002). Durante a campanha presidencial um dos candidatos a presidente, o $\mathrm{Sr}^{\circ}$ José Serra, colocou como uma de suas metas de governo cursos preparatórios gratuitos ao vestibular para os pobres, no dia 25 de agosto (FOLHA, 2002).

Essas ações e esse cotidiano de conflito e estabelecimento de pautas de negociação com o Estado configuram um movimento social. Segundo Gohn (2000), "Movimentos sociais são ações sociopolíticas construídas por atores sociais coletivos pertencentes a diferentes classes e camadas sociais", e na atuação dos cursos pré-vestibulares populares é possível identificar setores sociais representados na luta pelo acesso à Educação Superior. Esses movimentos também têm "ações que se estruturam a partir de repertórios criados sobre temas e problemas em conflitos, litígios e disputas vivenciados pelo grupo... a partir dos interesses em comum"(GOHN,2000). Os cursos apresentam ações em busca da inclusão na universidade, que se torna cada vez mais necessária à participação no mercado de trabalho e na inclusão social, e esses movimentos criam uma identidade própria: os negros, os estudantes de escolas públicas, as pessoas de renda mais baixa, aqueles que são desprivilegiados pelo sistema.

Ainda pela definição de Gohn (2000), "esta identidade é amalgamada pela força do princípio da solidariedade e construída a partir da base referencial de valores culturais e políticos compartilhados pelo grupo, em espaços coletivos não-institucionalizados". A análise dos documentos do Seminário do Fórum dos Quilombos Educacionais da Bahia, realizado dias 23 e 24 de janeiro de 2003, mostra essa identidade coletiva criada em símbolos de resistência contra a dominação, os "quilombos", adaptados para a realidade atual de disputa no campo da educação: são "quilombos educacionais", mas têm o mesmo objetivo de lutar pela libertação do "povo negro", nomenclatura sempre usada para criar a identidade e a força motriz dos projetos do movimento. No manifesto do seminário podemos ler:

Diante das questões levantadas pela Pastoral Afro Brasileira da Igreja Católica de Salvador, acerca da constatação da quase inexistência de negros nas universidades baianas, não obstante as iniciativas de grupos e cooperativas surgidos do Movimento Negro, foi idealizado o Seminário 
Sobre Educacional para a Comunidade negra. Este seminário, promovido pelo CAAPA (Centro Arquidiocesano de Articulação da Pastoral Afro), realizado em outubro de 2001, teve como objetivo discutir a educação na Bahia e, particularmente, o ingresso e permanência da população negra nas Universidades. O Seminário contou com a participação de 10 entidades que trabalham no campo da educação para a população afro-descendente da Bahia." (FÓRUM, 2003)

A necessidade de reflexão para estabelecer uma estratégia para a inclusão social comprova a hipótese de que os cursos não são somente para preparação dos alunos para enfrentar as provas do vestibular, mas têm o interesse de disputar os recursos públicos disponíveis na sociedade para mudar a situação de apropriação desses recursos, no caso, a Educação Superior, para um setor historicamente excluído. É claramente um movimento social que se propõe a trabalhar com um público específico, os afrodescendentes.

Ainda com relação à característica dos movimentos sociais de que eles interferem sobre a luta política do País, o Movimento dos Sem Universidade (MSU), quando propôs a constituição de uma universidade pela Prefeitura de São Paulo, fez um movimento para que fosse feita essa instalação no ex-presídio do Carandiru. Várias reuniões foram feitas para mobilizar as pessoas, com repercussão nos meios de comunicação e inclusive uma manifestação ocorreu, no dia 17 de agosto de 2002, um dia de sábado às 13 horas, com o lema de convocatória: "Marcha Cultural ao Carandiru: Por universidade pública e popular no Carandiru. Dez anos do massacre do Carandiru. Por uma cultura de vida. Pelo fim da cultura de morte". A manifestação foi uma passeata da Fatec, próximo ao metrô Tiradentes até o Carandiru. No mesmo mês de agosto de 2002, dia 23, sexta, o MSU entregou o Relatório Final do Grupo de Trabalho Sobre a Questão Universitária em São Paulo para a Prefeita Marta Suplicy. O grupo de trabalho foi constituído pela prefeitura como resposta às pressões feitas pelo movimento.

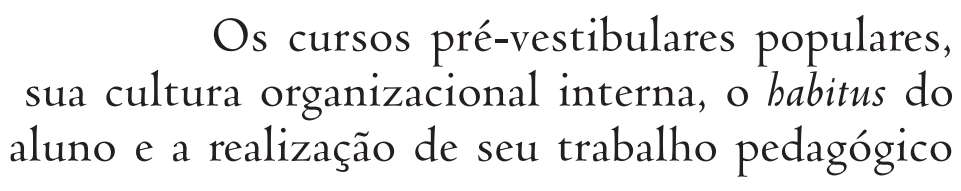

Tentamos estabelecer uma identificação da correlação entre o trabalho pedagógico das iniciativas dos cursos pré-vestibulares 
populares e o cumprimento dos objetivos dos cursos pré-vestibulares populares de inculcar os valores de cidadania ativa, etnicidade e luta pela justiça, assim como comparamos o habitus anterior desses alunos com a proposta do curso. Também realizamos a observação da cultura organizacional interna desses cursos.

Pudemos confirmar a hipótese inicial de que o trabalho pedagógico existe, sempre orientado pelo interesse da coordenação dos cursos em trabalhar com a cidadania ativa, com a valorização da participação social, com o sentimento de pertença e de solidariedade, mas esse trabalho pedagógico é limitado por vários elementos: 1) o pouco tempo do curso, apenas um ano; 2) pela demanda que os alunos têm de se preparar para o vestibular nesse pouco tempo e sua expectativa de priorizar a preparação para as provas de uma maneira tradicional; 3) pela precariedade das condições de trabalho e funcionamento das experiências desses cursos; e 4) pelo fato de que os alunos não são vazios de cultura, ou seja, eles têm uma vivência anterior ao curso e assim não é possível dizer que as experiências dos cursos populares são responsáveis por uma mudança profunda para a maioria dos alunos.

A maioria esmagadora dos alunos nos cursos Oficina de Cidadania e do Centro Dom Lucas Moreira Neves, (cerca de 95\% deles) 62 e 20 alunos respectivamente, admitem que já tinham conhecimento da existência do racismo, da discriminação racial e do que é a cultura negra. Um contingente bem menor já tinha participação em movimentos sociais, 31 e 10 alunos, respectivamente. O interessante a ser notado é que a dedicação ao curso acaba tirando o tempo de participar dos movimentos. Por outro lado, aqueles alunos que não tinham participação em movimentos, embora reconheçam a importância desses movimentos, não começaram a participar devido ao tempo dedicado aos estudos.

Um aspecto positivo apontado por praticamente todos os alunos foi a criação nos cursos de um espaço para debate e discussão de problemas sociais. O contingente de alunos que freqüenta esses cursos populares em sua maioria trabalha durante o dia e raramente tem oportunidade de acompanhar o noticiário jornalístico com as principais notícias do Brasil e do mundo. O curso acaba se constituindo no espaço para o contato com conhecimentos da atualidade, dos debates sociais mais candentes e de muitos conhecimentos não vistos na escola pública. Os cursos também se convertem em espaços para a expressão das idéias 
desses alunos, e a participação é apreciada por eles pela oportunidade da interatividade com outros colegas e professores. A relação com os professores é apreciada pelos alunos, pois esta se dá numa situação de maior proximidade, e muitas vezes de uma postura mais adulta no tratamento dos discentes.

Um ponto a considerar na cultura organizacional dos cursos é a questão docente. A dinâmica profissional do docente no Brasil, com baixa remuneração, é ter múltiplos empregos e a não poder se dedicar a nenhum deles em específico, e isso se repete na realidade dos cursos pré-vestibulares populares, com várias repercussões. O docente no Brasil é um dos menos valorizados do mundo, segundo estatísticas da própria UNESCO, e um trabalho voluntário ou com uma pequena ajuda de custo não estimula a permanência ou dedicação dos docentes aos cursos pré-vestibulares populares, por motivo de sobrevivência. Isso acaba provocando uma alta rotatividade de professores durante um ano de atividades desses cursos.

As reuniões pedagógicas são poucas para socializar os professores, pelas razões indicadas acima, sobrando pouco tempo disponível destinado a debater um projeto político-pedagógico diferenciado. As aulas acabam ocorrendo dentro da dinâmica dos cursos tradicionais, muitas vezes, até porque a expectativa dos alunos é que se cumpra o programa e que se prepare para o vestibular de um lado, e há falta de tempo dos professores do outro para preparar uma didática diferente, premidos que são pelos múltiplos empregos, pela extensão incomum dos programas dos vestibulares e pela falta de apoio pedagógico especializado.

Quando não há tempo e recursos para repensar a prática pedagógica, o que ocorre é a repetição da prática pedagógica hegemônica, de caráter conteudístico, aligeirado, superficial e competitivo para enfrentar as provas do vestibular. Percebe-se que há uma diferenciação entre os professores das equipes dos cursos populares, com relação ao engajamento nas atividades desses cursos, e não poderia ser diferente com as solicitações de sobrevivência deles. Há aqueles mais inteirados nas atividades, os parcialmente interessados, os participantes ocasionais e ainda os professores iniciantes em busca de prática pedagógica antes de tentar o emprego em alguma escola formal.

A possibilidade de ter um material pedagógico diferente dos cursos tradicionais ainda está remota para a Oficina de Cidada- 
nia e para o Curso Dom Lucas Moreira Neves. Esses dois cursos ainda trabalham com módulos de cursos comerciais tradicionais, o que compromete bastante a idéia de se diferenciar na proposta pedagógica. Há o Fórum dos Cursos que trabalha a perspectiva afrodescendente, que vem anunciando a produção de um material pedagógico diferente e específico para o seu projeto políticopedagógico. Apesar dos pedidos para termos contato a esse material, feitos aos coordenadores do fórum, não tivemos ainda acesso ao material para uma análise.

As relações internas nos cursos são mais horizontais do que nos cursos tradicionais, tanto entre os docentes e a coordenação como entre os docentes e os alunos, com um grau de informalismo e des-hierarquização acentuado. As reuniões realizadas entre os professores do curso Oficina de Cidadania e outras entre os cursos populares por ocasião dos encontros do Programa Diversidade na Universidade demonstram o idealismo, o voluntarismo e a disponibilidade de trabalho das coordenações dos cursos, que são notáveis. Mas, analisando as reais condições objetivas de trabalho do curso e sua cultura organizacional, percebemos que eles se situam numa dicotomia, numa aporia que resume sua existência: ideal X real.

O ideal é o motivador, o conjunto de valores, crenças e a mística que mantém as aulas funcionando, coesiona o grupo e permite o estabelecimento de parcerias para conseguir o espaço cedido de alguma outra instituição, conseguir o trabalho voluntário dos professores. Sem esse aspecto simbólico não haveria essas iniciativas. Podemos circunscrevê-las nas experiências que dão certo por liderança forte e pelo carisma que seus líderes e/ou seus ideais exercem na equipe de professores e de alunos que, muitas vezes, voltam para o curso depois de passarem nos vestibulares para lecionar, formando efetivamente uma comunidade, com identidade, distinção em relação ao meio, mitos e sonhos que alimentam as ações diárias.

Essas ações diárias ocorrem tanto nos cursos quanto nos movimentos, para os quais vários voltam após os vestibulares, depois do período mais difícil de estudos, tensão e dedicação acadêmica. A constatação do aumento dos quadros no movimento negro e outros movimentos é feita pelos relatos dos coordenadores, tanto do Asantewaa, que testemunhou esses fenômenos nos cursos ligados ao movimento negro de forma geral, quanto das coor- 
denadoras do curso dom Lucas Moreira Neves e no curso Oficina de Cidadania, que já conta com um terço dos professores atuais formados por ex-alunos das duas primeiras turmas do curso.

Por outro lado, há o "real" dos cursos pré-vestibulares populares, de ser uma modalidade de educação não-formal, com o objetivo de inclusão, mas sem o caráter de sustentabilidade alcançado por cursos educacionais comerciais ou pela rede formal de ensino que tem o financiamento do Estado, com todas as conseqüências indicadas anteriormente.

Como toda experiência social e educacional, os cursos pré-vestibulares populares encerram contradições. Há forte constatação de que os movimentos sociais souberam auscultar a sociedade e suas necessidades e perceberam a imensa demanda pelo ensino médio e superior iniciada na década de 1990. Essa percepção permitiu que esses movimentos, ONGs, movimento negro, igrejas participassem dessa demanda social, efetivamente se ligando a um genuíno anseio popular por melhoria das condições de vida e ascensão profissional, e, ao participar da vida de centenas de milhares de pessoas (se contabilizarmos os alunos que participam das redes de cursos populares em todo o Brasil poderemos estimar essa ordem de grandeza), os movimentos puderam empreender uma disputa de hegemonia de valores de conceitos, de concepções de mundo.

Fazendo o "accontability" dessas experiências, com de um lado suas dificuldades estruturais e, de outro, mitos e ideais motivadores junto à efetiva mobilização de pressões sociais sobre o Estado, podemos perceber que estamos diante de um momento interessante da educação e dos movimentos sociais no Brasil. Trata-se de um momento de reivindicação de movimentos, e ao mesmo tempo uma oportunidade profícua para analisar e aprender como se constituem e se expressam os valores que motivam lideranças a empreender iniciativas de educação não-formal de caráter popular e o interesse de formar redes sociais e intelectuais orgânicos. Os cursos estão sempre mantendo uma tensão com o sistema pré-estabelecido, se nutrindo dele para conseguir alunos em busca de vagas nas universidades, e ao mesmo tempo demandando pela expansão e pela mudança qualitativa do sistema. E, por fim, os cursos servem de espaço de pesquisa para a identificação de formas de educação que se estruturam e se reproduzem pela presença de ideais, lideranças e motivações socioculturais, servindo para a reflexão na esfera da educação formal. 
ABSTRACT: The text describes the research about the non-formal education experience of "pré-vestibular" courses in Salvador, their history and the atual situation of their organizacional culture. These experiences belong to social movements and they seek the empowerment of the values of citizenship, ethnicity and solidarity.

KEY WORDS: social moviments, university, interculturalism

\section{Referências}

BOURDIEU, P., PASSERON, J.C. A Reprodução: elementos para uma teoria do sistema de ensino. Tradução de Reynaldo Beirão. 2 ed. Rio de Janeiro: Livraria Francisco Alves, 1982.

BOURDIEU, Pierre. O Poder Simbólico. Rio de Janeiro: Bertrand Brasil, 2001. 322 p.

DALLARI, Dalmo de Abreu. Direitos Humanos e Cidadania. São Paulo: Moderna, 1998.

FERREIRA, Nilda Teves. Cidadania: uma questão de educação. Rio de Janeiro: Nova Fronteira, 1993.

FÓRUM DOS QUILOMBOS EDUCACIONAIS DO ESTADO DA BAHIA. Histórico do Fórum dos Quilombos Educacionais do Estado da Bahia. Re: lucas@yahoo.com.br [mensagem pessoal]. Mensagem recebida por<penildonfilho@hotmail.com> em 4 jan 2003.

GOHN, Maria da Glória. Teoria dos Movimentos Sociais. São Paulo: Loyola, 2000.

GOHN, Maria da Glória. História dos movimentos e lutas sociais: a construção da cidadania dos brasileiros. São Paulo: Loyola, 1995.

GUIMARÃES, Sônia. Como se faz a Indústria do Vestibular. Petrópolis: Vozes, 1984.

KUPER, Adam. Cultura: a visão dos antropólogos. Bauru, SP: EDUSC, 2002.

LA BELE, Thomas. Nonformal Education in Latin America and the Caribbean.Stability, Roform or Revolution? Nova York: Praeger, 1986.

MEC-INEP Censo da Educação do Ensino Superior. 1999. Disponível em: <http://www.mec.gov.br > Acesso em: 3 jun. 2001.

MEC-INEP. A Universidade de 1980 a 1998: Relatório do INEP, 2001. Disponível em: <http://www.mec.gov.br > Acesso em 3 de jun. 2001.

MELUCCI, Alberto. A Invenção do Prsene: movimentos sociais nas sociedades complexas. Petrópolis, RJ: Vozes, 2001.

OLIVEIRA, Roberto Cardoso de. Identidade, Etnia e Estrutura Social. São Paulo: Livraria Pioneira Editora, 1976. 
SEMPRINI, Andréa. Interculturalismo. Bauru, SP: EDUSC, 1999.

TEIXEIRA, Lúcia Helena G. Cultura Organizacional da Escola: Uma Perspectiva de Análise e Conhecimento da Unidade Escolar in Revista Brasileira de Política e Administração da Educação. Associação Nacional de Política e Administração da Educação. V16, n 1, p 7-22(jan./ jun. 2000) Porto Alegre: ANPAE, 2000.

TOURAIne, Alain. O que é democracia. Petrópolis, RJ: Vozes, 1994. 